\title{
Leukocyte chemotactic factor 2 related amyloidosis presented with severe jaundice and hepatic encephalopathy.
}

\author{
Hussam Almasri ${ }^{1}$, Abdo Lutf ${ }^{1}$, Almurtada Razok ${ }^{1}$, Ahmed Badi $^{1}$, Muneera Almohannadi ${ }^{1}$, \\ Mahir Petkar ${ }^{1}$, and Abdel-Naser Elzouki ${ }^{1}$ \\ ${ }^{1}$ Hamad Medical Corporation
}

October 4, 2021

\begin{abstract}
One of the most recently identified types is Leukocyte chemotactic factor 2 amyloidosis (LECT 2) which was found to be common in certain ethnic backgrounds. It is suggested that the diagnosis of this type is vital to prevent any therapy-related complications when it is erroneously diagnosed as AL amyloidosis.
\end{abstract}

\section{Introduction:}

Leukocyte chemotactic factor 2 amyloidosis (ALect2) is a recently recognized type of amyloidosis, common involvement of the kidneys with infrequent proteinuria and slow progression, rare involvement of the heart, relatively benign course and ethnic distribution are special characteristics that differentiate Alect2 from other types of amyloidosis (1).

Most cases of Alect2 were diagnosed in patients of Hispanic descent, also it was described to be common in Punjabi and native American ethnic groups $(1,2)$.

Liver involvement is usually subclinical and likely to be underdiagnosed in Alect2, more commonly seen in autopsy studies. The presentation of hepatic disease is usually mild hepatocellular injury or isolated elevation of alkaline phosphatase and rarely severe disease (1).

Diagnosis of this disorder usually is made with special stain done on kidney or liver biopsies (3).

The management is usually supportive of the renal disease and there is no definite treatment, however, it is important to identify this type of amyloidosis to avoid unnecessary and sometimes toxic treatment if it is erroneously diagnosed as AL or AA which are more common amyloidosis subtypes (3).

We encountered a case of a Punjabi-descent man who presented with jaundice and hepatic encephalopathy and was diagnosed with liver biopsy.

\section{Case presentation:}

A 53-year-old Indian gentleman with a history of hypothyroidism, systemic hypertension, and diabetes mellitus type II complicated by retinopathy and presumably nephropathy under conservative and follow-up management, presented to our hospital with a chief complaint of jaundice. The patient noticed yellowish discoloration of his eyes and skin that gradually progressed over one week. Other complaints included generalized, intermittent pruritus that started one month before and was more noticeable in the palms and soles, in addition to passing dark-colored urine.

There was no history of abdominal pain, nausea, vomiting, fever, weight loss, or altered bowel habits. The patient is a never smoker with no history of alcohol consumption or use of any kind of recreational drugs. 
There was no history of recent travel or change in dietary habits. He worked as a truck driver. Family history was negative. His home medications were sodium bicarbonate, linagliptin, levothyroxine, irbesartan, hydralazine, and furosemide.

Physical examination revealed generalized jaundice in the skin and sclerae. No organomegaly.

Laboratory workup revealed direct hyperbilirubinemia and elevated alkaline phosphatase and aminotransferases Table 1. The patient was admitted as a case of painless jaundice for investigation. Ultrasound of the abdomen and Magnetic resonance cholangiopancreatography (MRCP) revealed cholecystolithiasis with unremarkable liver texture, no intrahepatic and extrahepatic duct dilation.

The importance of identifying this disease is to avoid toxic chemotherapy when it is diagnosed as AL amyloidosis. This case is to raise awareness about this type of amyloidosis and the possibility of severe hepatic disease presentation.

As the patient's liver and kidney function tests were gradually worsening over one week, this prompted more invasive investigations. Endoscopic ultrasound was done to rule out a pancreatic mass that was not detected on MRCP and revealed a lymph node with a size of $18 \mathrm{x} 15 \mathrm{~mm}$ at the porta hepatis. Fine needle aspiration biopsy of the lymph node showed reactive lymphocytosis otherwise not suggestive of a specific pathology.

A percutaneous ultrasound-guided liver biopsy was done. Unfortunately, the liver biopsy was complicated by acute hemoperitoneum which necessitated admission into the medical intensive care unit and initiation of hemodialysis due to acute worsening of his renal function.

The liver biopsy revealed prominent globular eosinophilic deposits, seen in the portal tracts and the sinusoids. These deposits were positive for Congo red staining, displaying apple-green birefringence. Background cholestasis was noted. The appearances were in keeping with globular hepatic amyloid, which is considered to be highly sensitive and specific for LECT2 amyloidosis (4) Figure 1, 2.

After disclosure of the diagnosis to the patient and explanation of the nature of the disease and its progressive course, he chose to go back to his home country as he wanted to spend more time with his family. He was discharged from our hospital after a four-week course in a stable condition.

We were not able to follow the patient after his travel.

Table 1: Lab investigations:

\begin{tabular}{|c|c|c|c|c|}
\hline & At Admission & After two weeks & $\begin{array}{l}\text { After four weeks } \\
\text { (Time of discharge) }\end{array}$ & Reference Range \\
\hline $\mathrm{Hb}(\mathrm{gm} / \mathrm{dL})$ & 8.3 & 8 & $\begin{array}{l}10.6 \text { (post } \\
\text { transfusion) }\end{array}$ & $13.5-17.5$ \\
\hline Platelet (K/uL) & 304 & 315 & 241 & $150-400$ \\
\hline INR & 1 & 1.6 & $\begin{array}{l}1.1 \text { (post FFP } \\
\text { administration) }\end{array}$ & $0.8-1.1$ \\
\hline $\begin{array}{l}\text { Total Bilirubin } \\
\text { (umol/L) }\end{array}$ & 116 & 357 & 650 & $2-17$ \\
\hline $\begin{array}{l}\text { Direct Bilirubin } \\
(\text { umol/L) }\end{array}$ & 110 & 325 & 400 & $0-5.1$ \\
\hline $\begin{array}{l}\text { Alkaline } \\
\text { phosphatase } \\
(\mathrm{U} / \mathrm{L})\end{array}$ & 687 & 561 & 1644 & $40-130$ \\
\hline $\begin{array}{l}\text { Gamma glutamyl } \\
\text { transferase }(\mathrm{U} / \mathrm{L})\end{array}$ & 478 & 398 & $\mathrm{~N} / \mathrm{A}$ & $10-71$ \\
\hline $\operatorname{ALT}(\mathrm{U} / \mathrm{L})$ & 176 & 70 & 30 & $0-40$ \\
\hline $\operatorname{AST}(\mathrm{U} / \mathrm{L})$ & 107 & 72 & 188 & $0-37$ \\
\hline
\end{tabular}




\begin{tabular}{lllll}
\hline & At Admission & After two weeks & $\begin{array}{l}\text { After four weeks } \\
\text { (Time of discharge) }\end{array}$ & Reference Range \\
\hline $\begin{array}{l}\text { Lactic acid } \\
\text { (mmol/L) }\end{array}$ & 0.9 & N/A & N/A & $0.5-2.2$ \\
Albumin (gm/L) & 32 & 22 & 15 & $35-52$ \\
Urea (mmol/L) & 18.2 & 26.7 & 13 & $2.76-8.07$ \\
$\begin{array}{l}\text { Creatinine } \\
\text { (umol/L) }\end{array}$ & 269 & 372 & 226 & $70-115$ \\
\hline
\end{tabular}

Discussion:

Amyloid is a term was first adopted in 1854 by Rudolph Virchow, first described by a German botanist Mattias Schleiden in 1838 as a plant starch, to refer to starch like bodies in the nervous system when exposed to iodine $(5,6)$.

Amyloidosis is a spectrum of disorders that share the pathology of misfolded protein accumulation in various organs in the body originating from diverse etiology. 30 types of protein were identified to cause amyloid formation which causes a toxic effect in the tissues (3).

The most common type of these proteins in the developed countries is derived from the immunoglobulin light chain namely AL, there is also the amyloid protein that is derived from amyloid A namely AA, and amyloid derived from transthyretin.

Another type, known to cause accumulation in patients with chronic kidney disease, is derived from B2 microglobulin. A minor percentage of amyloidosis cases are hereditary.

Large case series showed that the most common type of amyloidosis is AL and AA in the US, but in the last few years, more case series emphasized that Lect2 amyloidosis is more common in the Hispanic population. Studies outside the US showed a common prevalence of Lect2 amyloidosis in middle eastern, Egyptian, Sudanese, Pakistani-Kashmiri and Punjabi-Indian, populations (2,3,7), our patient was Punjabi descent.

Lect2 is a chemotactic factor for neutrophils and it has a role in chondrocytes and osteoblasts stimulation. It is mainly produced by the liver and it is overexpressed in hepatocellular carcinoma and other liver diseases, it was suggested that Lect2 is an acute phase reactant produced as a response to hepatic inflammation and it plays a role in hepatic regeneration $(1,3)$.

Lect2 amyloidosis is not hereditary although some familial cases were described, the gene of this protein is located on chromosome 5 (5q31.1-q32) but abnormality on chromosome 7 was also reported. All cases in one case series by Rezk et al. except for one were found to be homozygous for the G allele and the other case was heterozygous $(1,7)$.

Said et al., reported a case series of 72 patients with renal Alect2 were mostly from the Hispanic population showed that nephrotic syndrome and haematuria were rare, up to one-third of the patients developed endstage renal disease in the duration of 26 months due to glomerular involvement (8).

Rezk et al. studied 24 patients with Lect2 amyloidosis and found that hepatic involvement was not associated with significant liver function derangement and none with cardiac involvement. This may be the reason behind its benign course in most cases (1).

The diagnosis is usually made by kidney or liver biopsy.

There is no specific treatment for Lect2 amyloidosis, most of the time, the treatment is supportive mainly directed for kidney disease (9).

The importance of identifying this disease is to avoid toxic chemotherapy when it is diagnosed as AL amyloidosis. More studies are needed to identify this subtype of amyloidosis and the possibility of severe hepatic 
disease presentation.

Author Contributions:

1. Hussam Almasri: corresponding author, manuscript writing

2. Abdo Lutf: clinical follow up

3. Almurtada Razok: manuscript writing

4. Ahmed Badi: clinical supervision

5. Muneera Almohannadi: clinical supervision

6. Mahir Petkar: pathology input

7. Abdelnaser Elzouki: manuscript review

References

1. Rezk T, Gilbertson JA, Rowczenio D, Bass P, Lachmann HJ, Wechalekar AD, et al. Diagnosis, pathogenesis and outcome in leucocyte chemotactic factor 2 (ALECT2) amyloidosis. Nephrol Dial Transplant. 2018 Feb 1;33(2):241-7.

2. Leukocyte cell-derived chemotaxin 2 (LECT2)-associated amyloidosis is a frequent cause of hepatic amyloidosis in the United States - PubMed [Internet]. [cited 2021 Sep 12]. Available from: https://pubmed.ncbi.nlm.nih.gov/24415538/

3. Picken MM. Alect2 amyloidosis: primum non nocere (first, do no harm). Kidney Int. 2014 Aug;86(2):22932 .

4. Chandan VS, Shah SS, Lam-Himlin DM, Petris GD, Mereuta OM, Dogan A, et al. Globular hepatic amyloid is highly sensitive and specific for LECT2 amyloidosis. Am J Surg Pathol. 2015 Apr;39(4):558-64.

5. Kyle RA. Amyloidosis: a convoluted story. Br J Haematol. 2001;114(3):529-38.

6. Sipe JD, Benson MD, Buxbaum JN, Ikeda S, Merlini G, Saraiva MJM, et al. Amyloid fibril protein nomenclature: 2012 recommendations from the Nomenclature Committee of the International Society of Amyloidosis. Amyloid Int J Exp Clin Investig Off J Int Soc Amyloidosis. 2012 Dec;19(4):167-70.

7. A C, P S, J C. Amyloidosis: The Newer Discovered ALECT2 Associated with der7q add(7). J Clin Diagn Res JCDR. 2016 Sep 1;10(9):ED04-5.

8. Said SM, Sethi S, Valeri AM, Chang A, Nast CC, Krahl L, et al. Characterization and outcomes of renal leukocyte chemotactic factor 2-associated amyloidosis. Kidney Int. 2014 Aug;86(2):370-7.

9. Jiménez-Zepeda VH, Leung N. ALECT2 amyloidosis: a new type of systemic amyloid highly prevalent in the Hispanic population. Rev Investig Clin Organo Hosp Enfermedades Nutr. 2014 Jun;66(3):269-73.

\section{Hosted file}

Figure 1.docx available at https://authorea.com/users/362403/articles/540377-leukocytechemotactic-factor-2-related-amyloidosis-presented-with-severe-jaundice-and-hepaticencephalopathy

\section{Hosted file}

Figure 2.docx available at https://authorea.com/users/362403/articles/540377-leukocytechemotactic-factor-2-related-amyloidosis-presented-with-severe-jaundice-and-hepaticencephalopathy 